$\begin{array}{ll}\text { Book Review } & \\ \text { Judul Buku } & \text { : Brainwashing: The Science of Thought Control } \\ \text { Penulis } & \text { : Kathleen Taylor } \\ \text { Penerbit } & \text { : Baca, Yogyakarta } \\ \text { Cetakan } & : \text { Pertama, } 2010 \\ \text { Tebal } & : 597 \text { halaman }+ \text { glosari \& indeks }\end{array}$

\title{
BRAINWASHING DALAM DINAMIKA RELASI AGAMA DAN NEGARA
}

\author{
Husain Haikal \\ Universitas Negeri Yogyakarta. \\ Email: h_haikal2005@yahoo.com
}

\section{A. Pendahuluan}

Dalam kenyataan sehari-hari tampak aneka peristiwa cuti otak telah wujud, merambah ke mana-mana dan menjadi fokus berita yang sering dikaitkan dengan dinamika peran bermakna mass media. Kenyataan pahit ini menjadi sejenis cuci mata bagi umumnya warga masyarakat yang telah jenuh dengan beragam kendala hidup sehari-hari. Mereka menghadapi aneka kesulitan sekedar mencari sesuap nasi untuk dirinya sendiri, apalagi keluarganya. Belum lagi kesulitan apabila mereka harus mencari tambahan biaya untuk sekolah anak-anaknya. Apabila mereka sakit, kesulitan makin bertambah sekedar untuk berobat hanya masalah berbelit birokrasi. Keadaan makin bertambah rumit apabila mereka miskin, apalagi bila tak punya uang. Saat berkendaraan mereka juga mengalami beragam kesulitan karena banyaknya polisi tidur. Bagi mereka polisi tidurpun sama mengganggu apalagi bila melek, terjaga. Sementara sebagian aparat terkait biasanya cenderung cuci tangan. Kenyataan ini mengu-atkan saling berkait antar pasar, negara, masyarakat, dan media. Sayang semua ini belum mampu melahirkan pengamalan demokrasi secara utuh dan 
menyeluruh. ${ }^{1}$ Peristiwa-peristiwa apakah yang telah menjadi santapan cuci mata dan aneka pihak terkait ramai-ramai sama cuci tangan? Sebelum dijawab, ada baiknya dikaji kutipan berikut: Kalau Anda ingin orang Islam marah, bakarlah masjid! Kalau Anda ingin orang Kristen marah, bakarlah gereja! Kalau Anda ingin keduanya saling serang, bakarlah masjid dan gereja! (Machiavellisme) ${ }^{2}$

Tampaknya tragedi yang menimpa tanah air Indonesia tercinta sedikit banyak terkait dengan sajian Machiavelli. Dia adalah politikus dan cendekiawan yang punya aneka kekhasan. Dalam salah satu karyanya yang paling dikenal, The Princes, figur ini telah menghalalkan segala cara untuk mencapai tujuan. Sikapnya demikian liberal, tak berpikir tentang moral apalagi coba mempertimbangkannya. Keadilan, kearifan, kasih sayang dan sejenisnya harus dapat dijauhi. Sementara teror, kekejaman, penindasan, dan suap menyuap adalah sah-sah saja. Benarlah apabila dikatakan: The end justifies the means, atau tujuan menghalalkan segala cara apa saja, yang penting tujuan tercapai. Hal yang sejenis ini tampaknya sedang mewabah di tanah air tercinta Republik Indonesia.

Relatif sejalan dengan hal tersebut, lewat mass media, terutama tv, insiden Cikeusik, Pandeglang, Banten, Jawa Barat jadi santapan sehari-hari. Belum usai dengan sajian ini, tiba-tiba bangsa Indonesia dikejutkan dengan amuk massa yang terjadi di Temanggung, Jawa Tengah. Dua peristiwa ini sekurang-kurangnya telah melahirkan tiga spekulasi yang dinilai sebagai penyebab terjadinya dua tragedi tersebut. Apa saja tiga spekulasi yang mampu melahirkan amarah massa yang meminta banyak korban dan nyawa tadi?

Ada yang menyebutkan semua ini akibat kemarahan umat akibat dari penistaan agama yang terlambat ditanggapi yang berkuasa. Atau lebih tepatnya minimnya pengetahuan warga masyarakat mengenai hukum yang berlaku. Sementara pihak lain mengatakan adanya kesengajaan pihak-pihak yang berkuasa untuk mendiskreditkan para tokoh agama yang pernah menyatakan pemerintah berbohong, sehingga mereka sebaiknya tidak mengurusi politik. Cukup mereka hanya mengurusi umat. Sedangkan spekulasi lainnya menyudutkan pihak-pihak yang konon sama mendompleng untuk mempercepat kejatuhan pemerintah. Semua ini dipercepat

1 C.f. Hermin Indah Wahyuni 2000, "Relasi Media Massa Indonesia dengan Negara, Masyarakat, dan Pasar dalam Orde Reformasi”, dalam Jurnal Ilmu Sosial dan Ilmu Politik. JSP,Vol. IV, No. 2, dimuat ulang dalam Nunung Prajarto (Ed.), Komunikasi Negara dan Masyarakat, (Yogya: Fisipol UGM, 2004), hal. 177

2 Taufik Hartono, "Skenario di Balik Penistaan Agama”, Republika, 14 Pebruari 2011, p. 2 
dengan munculnya dua peristiwa yang mencoreng wajah bangsa Indonesia yang semula dikenal sebagai bangsa yang anggun dan santun. Adakah pandangan aneka pihak tentang dua tragedi ini?

\section{B. Bersanding atau Bertanding?}

Dalam suasana prihatin ini seorang cendekiawan yang dikenal sebagai Direktur Sekolah Pascasarjana Universitas Islam Negeri Jakarta, Azyumardi Azra, tampil cukup vokal. Dia berani menyatakan bila ada motif mendiskreditkan para tokoh agama yang pernah mengeluarkan pernyataan kritisnya terkait kinerja pemerintah akan sia-sia. Wajarlah apabila ada pihak-pihak tertentu sama menganggap mereka ingin menjatuhkan pemerintah, sejalan dengan dua tragedi Cikeusik dan amuk massa di Temanggung. Hanya semua ini dinilai sia-sia dan tidak pernah berhasil. Dengan aneka motif yang dinilai akan menyudutkan pemerintah tersebut justru dapat membahayakan dan menghancurkan kesatuan serta persatuan bangsa. Mudah dipahami bila Azyumardi, sangat berharap agar Kepolisian Negara RI bersegera mengungkapkan secara tuntas motif dan latar belakang rangkaian dua tragedi tersebut. Bukankah sudah masanya semua pihak sama duduk bersanding dan berbincang mencoba memecahkan masalah secara bersama? Bukankah tiba masanya menghindarkan sikap apalagi tindakan yang akan menjurus ke arah tindakan untuk bertanding? Apalagi bagi semua pihak yang beriman, beragama.

Dua tragedi ini dapat sejalan dengan makna tersembunyi sebagian lirik lagu Andai Aku Jadi Gayus. Sebenarnya lagu ini awalnya berjudul Kisah Hidupku, gubahan Bona Paputungan, seorang narapidana. Dia merasakan getirnya hidup di penjara. Serba kegetiran ini mampu dia tuangkan dalam lirik yang digubah mendekati masa bebasnya pada 5 Januari 2011.

Dengan menghayati lirik gubahan Bona Paputungan, wajar bila aneka motif yang dianggap menyudutkan seperti itu justru dinilai akan membahayakan dan menghancurkan kesatuan serta persatuan bangsa. Mudah dipahami apabila Azyumardi berharap agar semua pihak sama waspada bukan curiga. Selanjutnya cendekiawan ini menandaskan sifat abai aparat terkait: "Kalau dilihat dari peristiwa dan informasi sebelumnya yang diketahui oleh aparat, seharusnya rangkaian peristiwa itu tidak perlu terjadi di Cikeusik, Pandeglang, Banten, dan Temanggung, Jawa Tengah. Oleh sebab itu, harus dicari tahu sungguh-sungguh apa sebenarnya yang terjadi." Selanjutnya Azyumardi juga menekankan bahwa masyarakat selama ini 
sudah cukup dewasa. Mereka benar-benar tambah jenuh mengetahui serta merasakan apa yang telah menjadi persoalan sehari-hari di bidang sosial dan ekonomi. "Kedua motif tersebut jika dikedepankan justru akan mempercepat eskalasi politik mengingat persoalan sosial ekonomi yang saat ini membebani masyarakat," lanjut Azyumardi. Bila ternyata dua motif itu benar, Indonesia semakin dekat dengan apa yang disebut kegagalan pemerintah dalam mengelola negara.

Tak hadirnya aparat tersebut sejalan dengan sajian mantan Rektor Universitas Gadjah Mada, Yogyakarta, Sofian Effendi. Pihaknya tidak menyoroti motif di balik peristiwa tersebut seperti tercermin dalam pandangannya. "Biarlah Polri yang mengungkap motif dan latar belakangnya. Bagi saya, peristiwa kemarin tidak ada hubungannya dengan konflik antar-agama. Mungkin yang paling utama adalah faktor tidak dirasakannya kehadiran pemerintah yang mengelola negara ini untuk melindungi dan mencegah terjadi aksi-aksi kekerasan.” Sofian juga mengakui, apabila perasaan masyarakat akan ketidakhadiran pemerintah untuk melindungi hak-hak mereka makin tinggi, dikhawatirkan akan terjadinya kegagalan Negara. ${ }^{3}$ Benarkah ini?

Setelah melapor pada Wakil Presiden Boediono, Kapolri Jenderal Timur Pradopo saat ditanya pers soal kemungkinan motif di balik insiden Cikeusik dan amuk massa di Temanggung untuk mendiskreditkan para tokoh agama dan motif pihak-pihak tertentu yang ingin sama mendompleng untuk mempercepat jatuhnya pemerintah, Jenderal Timur hanya menjawab: "Sekali lagi, langkah pengungkapan yang dilakukan Polri akan didasarkan pada fakta hukum yang akan dikembangkan dari hasil penyelidikan dan penyidikan," kata Kapolri. Selanjutnya?

Tragedi yang meminta banyak korban nyawa dan harta telah melahirkan mutasi pimpinan kepolisian. Antara lain Kapolda Banten Brigjen Agus Kusnadi dicopot, digantikan Brigjen Putut Putut Eko Bayuseno,Wakapolda Metro Jaya ${ }^{4}$. Hanya saja masih ada sejenis teka-teki di kalang-an penegak hukum. Salah satunya tampak saat persidangan Abu Bakar Ba'asyir yang dituduh dengan berbagai pasal berlapis. Apalagi ada banyak pengunjung gelap yang selalu hadir pada setiap persidangan Ba'asyir.

3 C. f. "Editorial Media Indonesa, "Manajemen Bingung" Sabtu 12 Pebruari 2011, hal. 1, yang antara lain mengatakan: “ . . bila kebijakan ekonomi terus diurus dengan manajemen bingung, posisi Indonesia yang kini disebut berada di ambang negara gagal bisa menjadi benar-benar gagal. Oleh karena itu, berhentilah main pingpong dengan kebi-jakan yang membingungkan pengusaha."

4 Media Indonesia, Sabtu 12 Pebruari 2011, hal. 1 
Kenyataan ini sejalan dengan pernyataan kuasa hukum Ba'asyir, Mohammad Assegaf: "Setiap persidangan Abu Bakar Ba'asyir, pasti yang datang itu misterius. Ia bukan wartawan, keluarga terdakwa, atau mahasiswa fakultas hukum," Sayangnya Assegaf tidak merinci lebih jauh siapakah para pengunjung misterius tadi. Hubungannya dengan cuci otak?

\section{Cuci Otak Awal Sekularisasi?}

Sajian di atas merupakan contoh-contoh nyata dari sejenis cuci mata yang sebenarnya berawal pada cuci otak seperti yang disajikan buku ini. Apa yang dikaji buku ini cukup berarti dan mudah dipahami. Mengapa? Buku setebal lebih dari 600 halaman ini mudah dinikmati karena sejumlah 597 halaman sajian yang berisi, terasa mudah dengan sajian tambahan berupa glosari yang cukup memadai sebanyak 16 halaman (699-614). Selanjutnya para pembaca lebih 'dimanja' dengan sajian berupa indeks sepanjang 23 halaman (615-637). Pada awalnya Taylor menyuguhkan reaksi pada tulisannya yang seakan memuji karena terkagum-kagum dengan mengucapkan dua patah kata sejenis, 'luar biasa'. Sementara pihak lain menanggapi secara agak sinis dengan mengucapkan semacam cibiran: "Cuci otak? Anda tentunya tahu kalau hal ini hanya omong kosong"(v). Cemoohan ini maupun pujian tadi bagi yang memiliki pemahaman dinamika sejarah Barat yang penuh dengan serba kekhasan wajar-wajar saja. Terbukti antar negara dan agama sering tidak mampu bersanding malah bertanding.

Salah satu kekhasan dunia Barat yang menjadi pusat kajian buku ini, adanya sejenis sikap renggang antar wahyu dan ilmu. Bahkan antar keduanya saling berhadapan dan coba saling menghancurkan dengan berbagai dalih dan kekuatan. Inilah yang melahirkan sekularisasi yang mudahnya dapat bermakna masalah dunia harus dipisahkan dari agama. Paham sekularisasi yang makin mantap sejak zaman Renaissance ${ }^{5}$ makin merebak ke mana-mana. Apalagi agama bagi dunia Barat hanya sekedar bagian dari budaya, Berbeda dengan Islam, agama atau tepatnya ad-din merupakan inti bagi budayanya. Salah satu contohnya tersaji dalam beberapa kalimat yang cukup bermakna berikut ini:

5 C. f. George Holmes (Ed.), The Oxford History of Medieval Europe, (Oxford: Oxford Un. 
The Modern Western World is inseperable from the idea of secularism. From Socrates' refusal to acknowledge the Greek gods to Copernicus' heretical idea that the Earth revolved around the sun to the French revolution's overthrow of clerical authority, the part of modernity has seemed to lead away from the claims of religion. In our own time, the decline of church attendance in Europe is seen as evidence that secular modernity has entered the lived of ordinary people. ${ }^{6}$

Sejalan dengan kutipan di atas, wajarlah bila Taylor menegaskan bahwa cuci otak benar-benar merupakan salah satu gagasan yang berbahaya ${ }^{7}$, katakanlah sebagai sebuah mimpi yang menyeramkan karena menerobos inti privasi atau pribadi seseorang. Tidak saja cuci otak yang mumpuni dan tidak hanya mengendalikan seluruh aspek atau segi tindakan seseorang, tetapi juga 'memandu' secara rinci pikirannya. Kekhasan cuci otak dengan aneka model ini jelas terungkap dalam salah satu contoh seperti yang tersaji dalam beberapa kalimat berikut ini:

Cuci otak bukanlah sebuah peluru ajaib, sebuah cara pintas untuk mengontrol pikiran. Cuci otak merupakan sebuah fenomena kompleks yang terus memanfaatkan prosesproses psikologisnya untuk mendatangkan malapetaka. Sementara itu, hal ini tampak menenangkan hati, konsekensinya adalah tidak ada pula peluru ajaib untuk "antipencuci otak".Cuci otak adalah sebuah fenomena social dan politis, dan pertahanan terbaik kita juga ada di ting-katan masyarakat: hanya politik yang bisa memaksimalkan perlindungan terhadapnya (ix).

Untuk lebih jelasnya perlu disajikan pula aneka korban cuci otak. Para korban tidak hanya para individu atau perorangan. Terbukti berdasarkan kajian yang lebih bermakna, para korban cuci otak tidak hanya mereka yang terpinggirkan, atau mereka yang sama sekali tidak masuk hitungan, tapi juga mereka yang sudah mantap. Bahkan mereka yang pilihan, yang telah diberi latihan dan dipersiapkan secara bermutu baik dengan ilmu serta beragam perlengkapan teknis. Mereka yang menjadi korban cuci otak dianggap berbagai pihak sebagai tragedi yang memalu-kan. Untuk lebih jelasnya tolong dikaji dalam beberapa kalimat berikut ini:

... suatu keanehan telah terjadi pada pasukan AS yang tertangkap oleh musuh [dalam Perang Korea]. Beberapa tentara yang keluar dari kamp tawanan perang jelas-

6 Erich Kaufmann, "Faith's Comeback How Democgraphics Will Reawaken Religion in Europe", Newsweek, November 13, 2006, hal. 34.

7 Sejalan dengan kenyataan ulah atau tingkah kasar dan meminta banyak kurban pada awal Pebruari telah menyebabkan mass media termasuk milik asing memberi label miring atau negatif pada Indonesia. Salah satunya tercermin dalam tulisan Philip Shiskin , "Intolerant Indonesia", Newsweek, Februari 21, 2011, hal. 36-8. 
jelas berubah menjadi pengikut Komunis,yang siap mencela tanah air mereka dan menyanyikan lagu-lagu pujaan untuk gaya hidup yang diajarkan Mao. Memang, fenomena tawanan yang dipaksa untuk menyanjung penangkapnya bukan lagi sesuatu yang baru (4).

Korban cuci otak sejenis di atas telah memicu lahirnya aneka ragam karya sastra. Karya sastra sejenis ini telah memberi ilham, atau memberi kesempatan bagi sutradara yang cukup jeli untuk lebih memantapkan lagi, khusus bagi mereka yang memerlukan hiburan Salah satu karya sastra tadi telah sempat difilmkan dan mampu menarik banyak peminat. Untuk lebih mudahnya tolong dikaji uraian beberapa kalimat berikut ini:

Film The Mancburian Candidate yang dirilis pada 1962, dibintangi oleh Frank Sinatra dan berdasarkan dari sebuah novel yang ditulis oleh Robert Condon pada 1959, menjadi sebuah cerita klasik mengenai kultus. Film ini mengisahkan seorang tentara Amerika [Serikat] yang diculik dan dicuci otak oleh Komunis China dan diprogram menjadi pembunuh bayaran yang bekerja untuk mereka (17).

Walau sebagian pembaca telah merasa sajian ini cukup membebani, tetapi para pembaca telah diberi sajian yang 'melezatkan' karena dalam Pengantar Taylor memberikan semacam ringkasan yang meliputi 15 bab uraiannya. Mudahnya 15 bab yang disajikan dapat dipilahkan dalam tiga bagian. Tiga bagian ini saling berkait satu dengan yang lain dan tak terpisahkan karena merupakan suatu kesatuan. Jelaslah apabila Pengantar ini lebih merupakan semacam Pendahuluan.

Semacam pendahuluan juga didapatkan dalam tragedi Cikeusik, seperti direkam dalam video yang diduga merupakan proses negosiasi antar Deden Sujana dengan Kanit Intel Polsek Cikeusik, Aiptu Hasan di rumah Suparman, sebelum bentrokan terjadi. Deden menolak ajakan Aiptu Hasan untuk dievakuasi, bahkan menjawab dengan cukup ketus: "Lepasin saja. Biar saja kita bentrok, biar seru. Kan asyik Pak. Masak kita diginiin diem saja Pak. Biar banjir darah di sini." Demikian kata Deden, dalam cuplikan pembicaraan yang terekam dalam video itu. Mende-ngar jawaban Deden, Hasan tegas mengatakan, "Saya sib tidak mengharapkan begitu." .

Tragedi di Temanggung dimulai dengan ulah Antonius Richmond Bawengan berusia 50 tahun. Dia berasal dari Manado, tetapi tinggal dan banyak beraktivitas di Jakarta. Tepatnya dia tinggal di Perumahan Pondok Kopi RT 001 RW 009, Kelurahan Pondok Kopi, Duren Sawit, Jakarta Timur. Dikabarkan pada Oktober 2010 dia berkelana ke Jawa Tengah. Sempat dia mampir ke rumah kerabatnya di

8 Lihat Bilal Ramadhan dan Rasyid Nurul Hakim , "Perekam Cikeusik Dilindungi", Republika, 12 Pebruari, 2011, hal. 11. C.f. sajian utama Tempo 20 Pebruari 2011. 
Temanggung. Dia tertangkap basah pada 23 Oktober 2010, saat tengah mengedarkan buku, brosur, dan selebaran yang isinya jelas-jelas menista agama. Tepat-nya dia ditangkap di Jalan Kyai Kenal RT 03/ RW III Kranggan, Temanggung. Dari berbagai karyanya tadi tampak dia tak hanya menista agama Islam, tetapi juga meremehkan Kristen dan Yahudi. Semua ini jelas terlihat dari bahasa yang digunakan dalam tulisan-tulisannya. Berbagai karyanya dihiasi dengan bahasa yang kasar dan penuh kebencian. Dia hanya mengaku suka melakukannya sendiri. Beberapa 'hasil karya' Antonius diantaranya, "Ya Tuhanku Tertipu Aku", "Selamatkan Diri dari Dajjal dan Kiamat". Setidaknya masih ada 17 buku, brosur, dan selebaran yang belum sempat disebar luaskan Antonius. ${ }^{9}$ Belum lagi terror bom buku, dan cuci otak pola NII yang mengharuskan para pengikut harus setor uang dstnya.

Agar memahami kenyataan menakutkan ini, baiknya sajian tiga bagian terjemahan karya Taylor Kathleen berjudul Brainwashing Ilmu tentang Pengendalian Pikiran, perlu segera dihidangkan. Semuanya berkaitan dengan cuci otak, jelasnya sebagai berikut:

Bagian I: Siksaan dan Godaan, terdiri dari 6 bab telah menyuguhkan sejarah dan psikhologi cuci otak yang meneliti aneka wilayah yang telah dirambahnya seperti agama ${ }^{10}$, kekerasan rumah tangga, kesehatan mental, pendidikan, media, ranah militer, dan sistem peradilan. Secara mudahnya cuci otak bercirikan penggunaan paksaan, tipuan, atau kedua-duanya. Terbiasa dalam teror cuci otak menimbulkan semacam trauma termasuk sebagian mereka yang masih mampu bertahan dan hampir tidak terpengaruh saat terkena musibah cuci otak. Tampaknya para cerdik cendekia Barat terkena sejenis cuci otak, atau lebih tepatnya punya prasangka amat buruk, apabila mereka 'bersentuhan' dengan Islam dan Rasulullah Saw, sekiranya disetujui kutipan berikut ini:

Western scholars denounced Islam as a blasphemous faith and its Prophet Muhammad as the Great Pretender, who had founded a violent religion of the sword in order to conquer the world. 'Mahomet' became a bogy to the people of Europe, used by mothers to frighten disobedient children. In Mummers' plays he was presented as the enemy of Western civilization, who fought our own brave St. George. ${ }^{11}$

9 C.f. sajian "Dakwah Berbelok Rusuh", Tempo 20 Pebruari 2011, hal. 36-7.

${ }^{10}$ Lihat karya-karya E. R. Chamberlin, The Bad Popes, The Black Death, dan The Fall of the House of Borgia.

11 Karen Amstrong, Mubammad A Biography of the Prophet, (New York: HarperSanFrancisco, 1993), hal. 11. 
Kenyataan yang mengagetkan dan memprihatinkan ini, apabila dunia Barat termasuk para cerdik cendekianya terkena sejenis cuci otak sejalan dengan tatapan mereka dalam menghadapi dinamika Islam dan Rasulullah Saw. Wajar bila perlu dipahami apa cuci otak itu? Ada beragam definisi tentang cuci otak, salah satunya adalah:

Cuci otak adalah sebuah tindakan yang disengaja; yaitu, perilaku dengan tujuan tertentu pada pihak si pencuci otak merupakan bagian inti cuci otak. Tujuan tindakan ini mungkin tidaklah buruk__ pencuci otak akan selalu meyakini bahwa korban akan mendapat manfaat dari 'edukasi ulang' - tetapi penilaian bahwa tindakan tersebut jahat tergantung pada perspektif yang digunakan .... (21)

Selanjutnya sajian bagian kedua terdiri dari 5 bab dan dikenal sebagai Bagian Pengkhianat di Kepala Anda, yang membahas neurosains. Bagian ini merupakan bagian yang tersulit karena membahas aneka hal yang berkaitan dengan saraf, yang mau tidak mau harus disajikan secara rinci dan tidak dapat dibahas secara singkat. Walau demikian bagi para pemula diberikan sejenis panduan, uraian neurosains secara singkat berupa diagram dan dasar-dasar teknis secara mini. Untuk memudahkan bagi sebagian para pembaca diberikan aneka contoh, walau tidak semuanya berhubungan dengan cuci otak. Mengapa? Bukti ilmiah dan langsung mengenai apa yang terjadi saat cuci otak berlangsung, tidak pernah ada karena bertentangan dengan etika yang disepakati bersama. Uraian panjang diperlukan karena kompleks atau rumitnya sajian mengenai perubahan otak, keyakinan, emosi, bagaimana otak menghasilkan tindakan, kontrol diri, dan kehendak bebas. Sajian ini membuktikan lukisan pikiran sebagai sesuatu yang solid, mantap, statis adalah hal yang keliru dan menyesatkan. Walau otak demikian berkilau dan dapat diumpamakan bagaikan sepotong berlian. Hanya saja berbeda dengan berlian, otak seakan tanah liat yang siap dibentuk karena beragam pengaruh dari luar, baik pengaruh secara alami, atau karena ulah atau kerja bermakna insan sebagai khalifah Tuhan. Jelaslah beragam perubahan terjadi akibat kerja bermakna atau ulah yang memprihatinkan dalam pergaulan sesama insan, atau dengan alam, serta sejenis ibadah pada Tuhan sebagai sang Khalik.

Bagian ketiga dari karya Taylor ini adalah Kebebasan dan Kontrol yang meliputi empat bab terakhir, yaitu bab 12 hingga 15. Diawali dengan sajian mengenai kekhasan pribadi yang rentan dengan cuci otak, atau kebalikannya sebagai predatornya. Semua ini terjadi terutama dalam kekuasaan totalitarian baik itu wujud dalam lembaga agama, apalagi dalam kekuasaan politik. Dalam kekuasaan agama zaman abad pertengahan yang dikenal sebagai middle ages, abad tengah. Abad tengah dikenal 
pula sebagai abad gelap atau dark ages. Mengapa abad tengah yang berlangsung selama sekitar 5 abad ini dikenal sebagai abad gelap. ${ }^{12}$ Mengapa? Masa berbilang abad terjadi serba kekosongan dalam perkembangan ilmu pengetahuan karena kuatnya dominasi peran gereja.

Apa yang disajikan buku ini cukup bermakna. Mengapa? Banyak hal yang dapat dikaji dari sajian Taylor ini. Tanpa disadari bangsa ini, terutama umat beragama apalagi muslim telah menjadi korban dari cuci otak, terutama dalam suasana global saat sekarang ini. Serba kenyataan pahit ini telah dimulai sejak zaman orde lama dan makin parah pada zaman orde baru, sekiranya disetuju sebagian isi disertasi berikut ini: "Banyak yang yakin bahwa pernyataan kembali kesalehan Soeharto [dan istri dengan melakukan haji-plus pada 1991] adalah percobaan untuk mengubah kebijaksanaan awalnya bahwa Islam adalah musuh negara—sehingga Islam tidak pernah mendapatkan perlindungan dalam Orde Baru."13

Bangsa Indonesia dihadapkan kenyataan yang memprihatinkan karena jati diri bangsa makin terabaikan dan hanyut dalam serba budaya materi. ${ }^{14}$ Semua ini dimulai dengan makin melimpahnya rezki akibat melambungnya harga minyak saat Indonesia masih menjadi negara pengekspor minyak. Untuk lebih jelasnya tolong direnungkan sajian berikut ini agar menjadi pelajaran berharga dan agar bangsa ini tidak bersikukuh dengan paham kapitalisme liberal yang selalu dibantah yang berkuasa.

Indonesia pada 1970-an adalah Indonesia yang dimanjakan petrodolar, ketika Pertamina yang seharusnya milik Republik itu praktis jadi kerajaan pribadi Letnan Jenderal Ibnu Sutowo dan keluarganya, ketika kekayaan para pejabat perusahaan itu berkilau-kilau, tersimpan hingga disudut-sudut yang jauh di luar negeri, ketika korupsi dan kemewahan membludak seperti tak akan berakhir-dan mungkin memang belum berarkhir. Kejiwaan yang dibentuk oleh uang yang licin, berkilau, dan melimpah dari barel demi barel itulah yang merupakan awal jalan sesat Indonesia. ${ }^{15}$.

12 C. f. E. R. Chamberlin sejenis EverydayLife in Renaissance Times, dan Life in Medieval France relatif cukup rinci menguraikan hidup yang penuh dengan serba keprihatinan bagi mereka yang menggunakan ilmu dalam menghadapi kendala kehidupan yang berada di bawah kendali gereja.

13 Moeslim Abdurrahman, Bersujud di Baitullah Ibadah Haji, Mencari Kesalehan Hidup, (Jakarta: Kompas, 2009), p. 74. Dalam kebijakan Orde Baru berkaitan dengan umat Islam dan umat beragama lainnya, dapat dikaji pula dalam aneka tulisan Ahmad Syafii Maarif, Amien Rais, atau tulisan Zuly Qodir. salah satu karya Zuly Qodir adalah Islam Syariah vis a vis Negara, (Yogya: Pustaka Pelajar. 2007).

14 Yuriani (2000), "Sentuhan Media Massa dan Status Sosial Ekonomi Kaitannya dengan Perilaku mengkonsumsi Makanan Tradisional”, Jurnal Penelitian dan Evaluasi, Th. II, No. 2., hal. 1-14.

15 Goenawan Mohamad, "BBM", Tempo, 15 Juni, 2008, hal, 154. 
Awal jalan sesat ini dimulai dengan pembiaran korupsi, bahkan ketika bangsa Indonesia dalam keadaan terjepit dan harus pinjam uang, terjadi peristiwa benarbenar tragis. Mengapa? Uang pinjaman tersebut secara beramai-ramai dikorupsi dengan aneka dalih, alasan. Lebih memprihatinkan lagi penyelewengan ini diketahui yang memberi pinjaman dan mereka pura-pura tidak tahu. Sejak lama korupsi dana pinjaman ini jelas-jelas diketahui Bank Dunia sendiri seperti disajikan Jeffrey A. Winters: "Dalam wawancara saya dengan pejabat-pejabat Bank Dunia di Jakarta dan AS, saya selalu dikejutkan oleh ketidak pedulian mereka dalam mengakui bahwa sepertiga dari [dana pinjaman] Bank Dunia dicuri. Saya setuju Bank Dunia seyogianya tidak berperilaku seperti sebuah kekuatan imperialis ... “16. Sekalipun jelas-jelas sepertiga dana pinjaman menguap karena dikorupsi, tapi tetap harus dibayar utuh ditambah bunga yang cukup mencekik oleh pemerintah Indonesia dengan menggunakan uang rakyat.. Kehidupan bangsa makin tergelincir karena kehilangan jati dirinya.. Dari soal yang remeh temeh hingga soal yang besar. Bayangkan dalam menu sehari-hari hampir selalunya sebagian besar bangsa ini disuapi dengan yang serba instan, serba jadi. Menu sehari-hari sejenis ini tidak terbatas pada golongan yang relatif terabaikan, atau kelas bawah, tetapi juga di kalangan warga kelas menengah, bahkan juga kelas atas. Sementara nilai tambah dari makanan tradisional terabaikan karena tidak pernah ditampilkan dalam iklan televisi.

Hanya saja sebagian dari warga kelas menengah dan atas relatif lebih sedikit agak beruntung. Mereka masih dapat menikmati menu tambahan, menu ekstra. Sayangnya mereka juga menjadi korban dari konspirasi global. Menu tambahan mereka juga bersifat cepat saji, hanya saja tampak lebih wah. Semua ini terjadi karena mereka seperti wong cilik atau kelas bawah dikejar-kejar waktu. Bila wong cilik diburu-buru waktu karena mencari sesuap nasi, maka kelas menengah dan atas diburu-buru waktu karena ingin segera bersantai-santai di tempat 'plesiran' seperti mall atau nonton dan bermain bola atau bilyard. Apabila mereka bersantai rumah entah nonton televisi atau sekedar ngrumpi. Apa saja menu tambahan mereka? Mereka umumnya sama memesan serba makanan sejenis kentucky fried chicken, atau pizza, atau burger. Makanan yang sama digemari mereka yang berduit ini di dunia barat dikenal sebagai junk food, atau makanan sampah.

16 Jeffrey A. Winters Dosa-dosa Politik Orde Baru, (Jakarta: Djambatan, 2009), hal. 59 C.f. Revrisond Baswir , Di Bawah Ancaman IMF, (Yogya: Pustaka Pelajar, 2003) 


\section{Penutup}

Cuci otak mempunyai akar yang cukup panjang dalam dinamika sejarah Barat. Tindakan sejenis ini konon terbiasa dilakukan mereka yang beriman di kalangan mereka yang hidup dalam genggaman gereja. Bahkan saat Eropa mulai dengan zaman pencerahan tindakan yang berkait dengan cuci otak tetap berlangsung, sekiranya disetujui sajian berikut ini:

Asosiasi modern antara "cuci otak" dan "mesin" telah lebih dahulu disinggung dalam 1790-an oleh James Tilly Matthews, seorang pedagang yang terjebak dalam peristiwa politik kejam yang menggelorakan Prancis, dan menggentarkan Inggris, pada saat itu. Perang pecah diantara kedua Negara menyusul Revolusi Prancis dan eksekusi raja Perancis Louis XVI pada 1793. (17-8)

Dunia Barat, termasuk AS juga melakukan hal sejenis dan mempunyai targettarget yang khas. Salah satunya terekam dalam kalimat berikut ini: "IRAQ, INDONESIA, NORTH KOREA, Where Next for America's War on Terror ? $^{17}$. Wajarlah apabila Abubakar Baasyir menjadi salah satu targetnya, dan ini telah diusahakan dalam berbagai kesempatan serta selalunya belum berhasil. Semua ini dapat dikaji dalam otobiografi Ahmad Syafii Maarif yang sekurang-kurangnya telah dua dicetak ulang. Kali pertama biografi ini diterbitkan Ombak, dan kemudian diterbitkan Mizan Dalam kaitan ini sajian Taylor cukup bermakna, salah satunya tercermin dalam kalimat berikut: “ . . . keengganan AS dan Israel saat ini untuk meng-eksplorasi argumen-argumen bahwa ketakutan, kemiskinan, dan penindasan memiliki kontribusi sangat besar terhadap aktivitas teroris dalam perlawanan Palestina. (19)" Bagi Indonesia, cukup bermakna apabila berkenan mencoba mengikuti apa yang telah disajikan Zuly Qodir, salah satu-nya tercermin dalam "Nabi Baru Versus Negara", seperti tersaji dalam Millah Vol. VII, No. 2, Februari 2008, atau bersikap seperti Pak Abdur Razak Fakhrudin, salah satunya tercermin dalam kutipan berikut:

Pak AR [panggilan akrab Pak Abdur Razak Fakhrudin] langsung mendatangi saya dan menyarankan agar saya sebagai pemuda Muhammadiyah, harus bersikap lebih toleran kepada pemuda NU. Ia menambahkan bahwa saya tidak harus merendahkan gagasan khilafiyah dan furuiyyah, pemahaman dan tatacara ritual yang berbeda, yang digolongkan sebagai cabang doktrin, bukanlah prinsip dasar itu sendiri. Namun ternyata, perselisihan seperti itu tidak pernah muncul lagi selama dalam perjalanan ke Mekkah. ${ }^{18}$

17 Sampul depan Newsweek (2002), 28 Oktober

18 Moeslim Abdurrahman, Bersujud di Baitullah ... p. 74. 
Atau pembaca mempunyai pandangan yang lain tentang bedah buku ini? Silahkan sajikan dalam jurnal ini agar terjadi serba kegairahan dalam dunia tulis menulis. Budaya tulis menulis relatif agak terabaikan dalam dinamika beragam lembaga pendidikan Indonesia pada umumnya, tanpa kecuali dunia perguruan tingginya.

\section{DAFTAR PUSTAKA}

Abdurrahman, Moeslim. 2009. Bersujud di Baitullab Ibadah Haji, Mencari Kesalehan Hidup. Jakarta: Kompas.

Baswir, Revrisond. 2003. Di Bawah Ancaman IMF. Yogya: Pustaka Pelajar.

Editorial Media Indonesia. 2011. "Manajemen Bingung”. Sabtu, 12 Pebruari.

Hartono, Taufik. 2011. "Skenario di Balik Penistaan Agama”. Republika, 14 Pebruari.

Holmes, George (Ed.) 2001. The Oxford History of Medieval Europe. Oxford Un. Press.

http:/ / kabarnet.wordpress.com/2011/01/16/inilah-lirik-lagu-andai-aku-gayustambunan/ accessed Senin 14 Pebruari 2011.

Indah, Hermin Wahyuni. 2000. Relasi Media Massa Indonesia dengan Negara, Masyarakat, dan Pasar dalam Orde Reformasi”, Jurnal Ilmu Sosial dan Ilmu Politik. JSP,Vol. IV, No. 2, dimuat ulang dalam Nunung Prajarto (Ed. 2004), Komunikasi Negara dan Masyarakat, Yogya: Fisipol UGM.

Karen, Amstrong. 1993. Mubammad A Biography of the Prophet. New York: HarperSan Francisco.

Kaufmann, Eric. 2006. "Faith's Comeback How Democgraphics Will Reawaken Religion in Europe". Newsweek, November 13.

Mohamad, Goenawan. 2008. "BBM”. Tempo, 15 Juni.

Navis, A.A. 1999. Filsafat dan Strategi Pendidikan M. Syafei. Jakarta: Grasindo.

Qodir, Zuly. 2007. Islam Syariah vis a vis Negara. Yogya: Pustaka Pelajar. .2008. "Nabi Baru Versus Negara", seperti tersaji dalam Millab Vol. VII, No. 2, Februari. 
Ramadhan, Bilal dan Rasyid Nurul Hakim. 2011. "Perekam Cikeusik Dlindungi”. Republika, 12 Pebruari.

Sampul depan Newsweek, 28 Oktober 2008.

Winters, Jeffrey A. 2009. Dosa-dosa Politik Orde Baru. Jakarta: Djambatan.

Yuriani. 2000. "Sentuhan Media Massa dan Status Sosial Ekonomi Kaitannya dengan Perilaku mengkonsumsi Makanan Tradisional”, Jurnal Penelitian dan Evaluasi, Th. II, No. 2 